Research Article

\title{
Impact of a Social Constructivist Instructional Strategy on Performance in Algebra with a Focus on Secondary School Students
}

\author{
Umar A. Ginga ${ }^{1}$ and Yusuf F. Zakariya ${ }^{2}{ }^{2}$ \\ ${ }^{1}$ Department of Science Education, Ahmadu Bello University, Zaria, Nigeria \\ ${ }^{2}$ Department of Mathematical Sciences, University of Agder, Kristiansand, Norway \\ Correspondence should be addressed to Yusuf F. Zakariya; yusuf.zakariya@uia.no
}

Received 24 February 2020; Revised 30 May 2020; Accepted 4 June 2020; Published 29 June 2020

Academic Editor: Elina Kuusisto

Copyright (c) 2020 Umar A. Ginga and Yusuf F. Zakariya. This is an open access article distributed under the Creative Commons Attribution License, which permits unrestricted use, distribution, and reproduction in any medium, provided the original work is properly cited.

\begin{abstract}
There have been perennial concerns on the low academic performance of students among researchers and other education stakeholders. Innovative teaching strategies have, therefore, gained prominence in the field of mathematics education. The purpose of this study is to investigate the impact of a social constructivist instructional strategy on students' performance in algebra. The present study is quasi-experimental, and its type is a posttest control group involving 154 secondary school students that are randomly selected across four intact classes. The random selection of students to treatment and control controls is assumed to improve the validity of the results. Two research questions are raised, and two null hypotheses are formulated and tested at $p \leq 0.05$ level of significance. One research instrument, algebra performance test (APT), was developed, pilot-tested (testretest reliability coefficient of 0.897 ), and used to measure students' performance in both treatment and control groups. The data are analyzed using independent sample $t$-tests. The findings indicate that there are significant differences in the mean performance scores between experimental (mean $=16.05, \mathrm{SD}=2.74$ ) and control (mean $=11.46, \mathrm{SD}=2.49$ ) groups, $t(152)=10.83, p<0.05$. These findings may be interpreted to be evidence of the effectiveness of the social constructivist instructional strategy in improving performance in algebra better than the conventional teaching method. Also, a significant difference exists between the mean performance scores of males $($ mean $=17.83, \mathrm{SD}=2.82)$ and females $($ mean $=14.72, \mathrm{SD}=1.77)$ in the experimental group $(t(80)=$ $6.11, p<0.05)$. Thus, the effect of the social constructivist instructional strategy on students' performance in algebra is gendersensitive. Based on these findings, some recommendations are made to students, teachers, parents, administrators, and other stakeholders.
\end{abstract}

\section{Introduction}

Mathematics is given adequate attention and emphasized in the Nigerian school curriculum, right from primary through secondary to tertiary institutions. It is a compulsory subject that must be passed at credit level by students before gaining admission into tertiary institutions in the country. Despite the effort of the government, teachers, and other education stakeholders including students, it is regrettable that many students continue to struggle with mathematics and perform low in both school-based and national examinations [1]. This is evident in the persistent students' low performance on national examinations such as the senior secondary school certificate examinations that are conducted by both the West African Examinations Council (WAEC) and National Examinations Council (NECO). For instance, the results obtained from the examination division of WAEC in a state in Nigeria reveal that the percentage of students that obtained credit pass and above in mathematics from 2005 to 2015 was between $4 \%$ and $15 \%$. This is a disheartening situation which if not given proper attention with urgency might affect the entire state not only in the education sector but also in other sectors.

Meanwhile, multiple studies have suggested that adopted instructional strategies in schools contribute immensely to 
students' learning outcomes. Kurumeh [2] argues in an empirical study that inappropriate, inadequate, and elitist teaching techniques and methods used by mathematics teachers are instrumental to learners' inability to understand and retain the basic mathematical principles, computations, or logical facts involved. In another study, Obioma [3] identified poor teaching strategy as one of the factors that impede students' understanding of mathematics which leads to poor performance in the subject. However, some researchers (e.g., [4]) have argued that mere change of instructional strategies might not necessarily lead to improved students' performance and those authentic instructional strategies should be laced with standards that foster intellectual quality. Others have also identified teacher efficacy as an important variable for a successful implementation of innovative teaching strategies to bring about improved performance in students (e.g., [5]). On this basis, several teaching and learning strategies have been proposed with their being effectiveness investigated in both quantitative and qualitative empirical studies.

For instance, in a meta-analysis study on the effectiveness of inquiry-based teaching on students' performance, Furtak et al. [6] found an effect size of .50 of the teaching method on students' performance. The inquiry-based method has been proven effective for not only teaching but also learning. This fact is substantiated by an increase in mathematics content knowledge of preservice teachers at the end of an inquirybased learning activity [7] and an improvement in students' metacognitive skills [8]. The efficacy of problem-based instructional strategy has also been demonstrated in a quasiexperimental study in which students who were taught algebra using the problem-based method outperformed those who were taught algebra using the conventional method on difficult mathematical tasks [9]. Similar corroborative findings on the effectiveness of problem-based instruction can also be found elsewhere $[10,11]$. The effectiveness of several other innovative teaching and learning strategies such as experiential strategy [12], discovery method [13], computermediated and use of computational tools in teaching strategy $[14,15]$, and project-based instruction [16] has been properly documented.

However, none of these promising reported efficacies of the innovative teaching and learning strategies focused on Nigerian secondary school students. Meanwhile, it could be erroneous to claim that findings from these studies outside the country are generalized to the Nigerian population given the inherent diverse cultural and economic differences, especially when there have recorded instances where some of these innovative teaching and learning strategies fail to improve students' learning outcomes (e.g., [17]). Thus, the main purpose of the current study is to provide empirical evidence for the impact of a social constructivist instructional strategy on performance in algebra among secondary school students. In specific terms, the current study attempts to address the following research questions:

(1) What is the difference between the mean scores of secondary school students taught algebra using a social constructivist instructional strategy and those taught algebra using the conventional teaching method?

(2) What is the difference between the mean scores of male and female secondary school students taught algebra using a social constructivist instructional strategy?

We focus on algebra in the current article because it has been identified as a very difficult topic in mathematics curriculum and creates some hurdles for students while learning the subject [18]. The problem of understanding number identification and symbols at primary levels permeates to secondary education. Evidence of this confusion can be found in national chief examiners' reports that have consistently identified algebra as an area of weakness over the past several years. There is also international evidence for a similar phenomenon (e.g., [19]). The arithmetic and algebraic skills of many upper secondary and even adult learners may remain at a very superficial level, even though the older learners may succeed a little better in a test assuming algebraic knowledge. A little variation in a task may result in a significant drop in task performance. This can be due to a superficial understanding of variables and formulas. Furthermore, we contrast a constructivist instructional strategy with a conventional teaching method (mostly characterized with teacher dominated classrooms and students' taking notes) in the current study because of the satisfactory performance of the former in culturally distinct societies (e.g., [20, 21]). The remaining part of this article is arranged such that a theoretical background is provided in the next section, followed by a section on methodological issues. Therein, issues related to the research design, sample and sampling procedure, validations of an instrument, and procedures for data collection and analysis are discussed. Results are presented in a separate section followed by a section on the discussion of major findings of the study and some concluding remarks, including strengths and potential limitations of the study.

\section{Theoretical Framework}

Social constructivism is a theoretical approach to teaching and learning that underpins the current study. This theoretically perspective draws heavily on the works of Lev Vygotsky with a fundamental assumption that emphasized a dynamic nondualistic interaction between individual and social processes in the coconstruction of knowledge. Social constructivism has witnessed increased attention in the last two decades when interests in behaviourism, cognitivism, radical constructivism, and information-processing perspectives continue to decline. This period has been tagged as a "social-cultural revolution" period by some researchers (e.g., [22]). Following the lines of thoughts of Vygotskian social-cultural perspective, knowledge in social constructivism is culturally situated, and learning takes place through the appropriateness of this knowledge as mediated by tools and artefacts [23]. Leaning in Vygotskian social-cultural perspective of constructivism precedes the development of internal processes in contrary to Piagetian perspective of 
constructivism that argues for the other way around. As such, the concept of the zone of proximal development was introduced by Vygotsky [24] and defined as "the distance between the actual developmental level as determined by independent problem-solving and the level of potential development as determined through problem-solving under adult guidance or in collaboration with more capable peers" (p. 86). Thus, an important component of the learning process is collaboration, as explicated by Vygotsky [24] as follows:

We propose that an essential feature of learning is that it creates a zone of proximal development; that is, learning awakens a variety of internal developmental processes that are able to operate only when the child is interacting with people in his environment and in cooperation with his peers. Once these processes are internalized, they become part of the child's independent developmental achievement. (p. 90)

Therefore, the role of a teacher in a social constructivist classroom is to facilitate and ensure such collaboration takesplace during a learning activity. Thus, the current study relies on a Vygotskian social constructivist model of teaching proposed in three stages by Johri [25] as follows:

(i) Stage one (observation): this is a stage where imitative and modeling learning takes place. Learners strive to imitate the teachers or more capable others by observing and practising the same learning activity.

(ii) Stage two (scaffolding or instructed learning): this is a stage where learners strive to appropriate teachers' and/or more capable others' instructions by listening. Scaffolding is a teacher's or more capable others' practice in the form of assistance that is rendered to a learner such that the learner's out-ofreach goals can be attained, or out-of-reach engagement can be achieved [26].

(iii) Stage three (collaborative learning): this stage describes a situation whereby a group of peers make every effort to understand each other such that learning that occurs in the process of knowledge is socially coconstructed among peers through discussion.

The social constructivist teaching strategy described in stages,from one to three, or a variant of it has been applied and found effective in improving students' learning outcomes (e.g., $[27,28])$. Thus, based on the aforementioned theoretical framework and the literature that has successfully applied a social constructivist teaching strategy, we hypothesize the following:

Hypothesis one (H01): there is a significant difference between the mean performance scores of secondary school students taught algebra using a social constructivist instructional strategy and those taught using the conventional method of teaching

Hypothesis two (H02): there is a significant difference between the mean performance scores of male and female secondary school students taught algebra using a social constructivist instructional strategy

\section{Methodology}

3.1. Research Design. The current study adopts a posttest control group quasi-experimental research design. This involves an experimental group whose students are taught algebra using a social constructivist instructional strategy and a control group whose students are taught algebra using the conventional method of teaching. The two groups are assumed to be relatively equivalent in their academic achievements before the treatment since they are both public school intact classes and are randomly assigned to the groups. Public schools are used in the current study becauseof their relative uniformity in terms of staffing, the population of students, teaching materials, the curriculum in use, learning environment, and other infrastructural facilities. Both the experimental group (EG) and the control group (CG) are posttested to determine the impact of the administered treatment.

3.2. Participants. A total of 200 year-two senior secondary school students who voluntarily consented to take part in the study constitute the sample of this study. The study focuses on year-two students because of their relative stability in schools and maturity. Unlike, year-one students are new to the senior secondary schools and year-three students who are preparing for their final national examinations. The individual student consent is sought using a pen and paper approach, and the confidentiality in processing their personal was ensured. They are made to realize that the data collected will be used for research purposes only, and there is no means through which they can be identified. Furthermore, their performance on the test that will be administered will neither add to nor subtract from their final grades in their ongoing mathematics subject, and there is no penalty for anyone who wishes not to participate in the study. A total of 46 students withdrew their consent and opted out of the study to give an effective sample of 154 secondary school students with an average age of 17 years. These include 82 students in the experimental group and 72 students in the control group. Furthermore, written consent was also sought from and approved by each school principal of the selected schools.

3.3. Instrumentation. The algebra performance test (APT) was developed by the researchers and used as a proxy to measure students' performance in algebra. The items on the test are derived from five subthemes of the algebra topic in senior secondary school one and senior secondary school two mathematics curricula. The subthemes include six questions each from simple quadratic equations, simultaneous linear and quadratic equations, linear inequalities, the gradient of a curve, and algebraic fractions. Sample questions in each subtheme are presented in Table 1 . The complete test instrument is available upon request from the corresponding author. The APT is a 30 -item multiple-choice test with four option categories (a-d). When constructing the test items for the APT, the researchers made sure that all the questions posed therein 
TABLE 1: Sample questions on the algebra performance test.

Subtheme Sample questions

(3) What must be added to $x^{2}+6 x$ to make the expression a perfect square?

(a) -4 (b) 9 (c) 4 (d) -9

Simple quadratic equations

(5) Find the sum and product of the roots of the equation $2 x^{2}-10 x+7=0$

(a) $(3,2)(b)(4,4)(c)(3,3)(d)(5,2)$

(7) Solve the simultaneous equations $2 x+5 y=1$, and $3 x-2 y=30$

(a) $x=8$ and $y=3$ (b) $x=8$ and $y=-3$

(c) $x=-8$ and $y=-3$ (d) $x=7$ and $y=-3$

Simultaneous linear and quadratic equations
(9) Seven cups and eight plates cost N 1750. Eight cups and seven plates cost N 1700. Calculate the cost of a cup and a plate.

(a) $\operatorname{cup}=\mathrm{N}$ 100: plate $=\mathrm{N} 120$ (b) cup $=\mathrm{N} 70$ : plate $=\mathrm{N} 130$

(c) cup $=\mathrm{N}$ 90: plate $=\mathrm{N} 140$ (d) cup $=\mathrm{N}$ 190: plate $=\mathrm{N} 240$

(14) Given that $x$ is an integer, find the three greatest values of $x$ which satisfy the inequality $7 x+$

$$
13<2 x
$$

Linear inequalities

(a) $-3,-4,-5$ (b) $3,4,-5$ (c) $-4,-4,-4$ (d) $3,4,5$

(18) Solve the following inequality $3<6-2 y$

(a) $y<1$ (b) $y=1(1 / 2)$ (c) $y>2(1 / 2)$ (d) $y<1(1 / 2)$

(20) Find the coordinates of the points where the line represented by the equation $y=2 x-2$ crosses the axes

(a) $(0,0),(1,0)($ b) $(0,2),(-1,0)$

(c) $(0,-3),(3,0)(\mathrm{d})(0,-2),(1,0)$

The gradient of a curve

(24) The gradient at any point on a curve is defined as

(a) The centre of a point

(b) The distance from that point

(c) The point and the distance

(d) The gradient of the tangent to the curve at that point

(29) Solve the equation $5-2 d=(2 / d)$

Algebraic fractions

(a) $1,-2$ (b) $(1 / 2), 2$ (c) $(1 / 3), 2$ (d) $-(1 / 2), 3$

(30) The value of $x$ for which the fraction $(3 /(x+2))$ is undefined is

(a) $x=-2$ (b) $x=2$ (c) $x=-3$ (d) $x=3$

are within the content area of the algebratopic and examined the cognitive level of the target students such that the items are not too difficult and not easy for the students to answer. The instrument was piloted in an independent but similar population before the commencement of the current study. The data obtained from the pilot study are used for test validations, item analysis, reliability, checking of the marginal errors for the test, and determination of the sample size. It is important to remark that the authors have used a 30-item test to assess the performance of students in algebra as it is typical of standard research-based assessment in the country and the unidimensionality of the APT is implicitly assumed.

The test validations are considered necessary such that the test is free from random and systematic errors. Some items on the test are restructured and amended by the researchers following the results from the validity checks. The APT was found to have face, content, and construct validity as the items captured the main construct of concern (topics on the algebra). The initial 45 items of the APT were subjected to item analysis to determine the item quality and reliability of the test. The results from the item analysis show that only 30 items on the APT have acceptable difficulty and discrimination indices as recommended in the literature (e.g., [29]). The testretest reliability coefficient of the 30 -item APT was found to be 0.897 using Pearson's correlation.
3.4. Data Analysis. Four research assistants (classroom teachers of selected schools) were recruited and trained on the use of the social constructivist strategy. They are experienced classroom teachers with several years of teaching secondary school mathematics. The researchers invited these research assistants for a discussion and rehearsal about the content of the strategy and how the teaching was to be conducted. In this workshop, each of them was given a copy of the manual, teaching guides, and lesson plans to scrutinize, ask questions, interact with colleagues, and make criticisms for further improvement or adjustment on its contents. There were also interactive sessions and demonstrations on how to adapt the new strategy in their respective classroom teaching of mathematics. The lesson guide provided to the research assistants features an introduction of the lesson, division of the classroom into sociable groups, assignment of roles to group members, the introduction of activities to groups using the social constructivist approach, discussions of students' results, evaluation of students' learning progress, and then the conclusion. The training exercise lasted for three weeks, where each of the research assistants is observed and graded. Two of the research assistants who are found to understand better the social constructivist instructional strategy were selected for the exercise. 
We proceed to treatment administration in which both the experimental and the control groups were taught for a period of six weeks. The experimental group was taught algebra using the social constructivist instructional strategy while the control group was taught algebra using conventional method teaching. The posttest APT was given immediately after the treatment period to the two groups. The options chosen by the students in the posttest APT were scored using the marking guide providing each correct answer with a score of one mark and a maximum obtainable score of 30 marks on the whole test. The collected data were checked for the assumptions of parametric testing before the analysis was conducted. These assumptions include that of the normal distribution, skewness, kurtosis, multicollinearity, and continuous level of measurement [30]. The data were found qualified for parametric testing, and the mean scores of students were compared using the independent samples $t$-test such that the hypotheses one and two could be tested at $p \leq 0.05$.

\section{Results}

In an attempt to test hypothesis one and confirm whether or not a significant mean difference exists between the performance scores of senior secondary school students taught algebra using a social constructivist instructional strategy and those taught algebra using the conventional method, we run an independent sample $t$-test. The posttest data collected are used for this purpose, and the analysis involves only one independent variable (teaching methods) with two levels (social constructivist instructional strategy and conventional method of teaching). The ensuing results from the analysis are presented in Table 2 .

The results in Table 2 indicate that there is a significant difference between the mean performance scores of students taught algebra using the social constructivist instructional strategy $(M=16.05, \mathrm{SD}=2.74)$ and those taught algebra using the conventional method of teaching $(M=11.46$, $\mathrm{SD}=2.49), t(152)=10.83, p<0.001$ (two-tailed), Cohen's $d$ squared of 0.44 . The magnitude of difference in the means (4.59) is within 95\% confidence interval (CI: 3.75 to 5.43), which shows that the mean difference is statistically large. This finding confirms Hypothesis one and can be interpreted to mean that the use of the social constructivist instructional strategy has a positive impact on students' performance by improving their scores at the class level. The effect size of this impact is found to be at medium level which can be interpreted to mean that $44 \%$ of the variance in performance scores between the experimental and the control groups is explained by the type of teaching method and not by chance. Furthermore, this finding corroborates the previous results of significant improvement in learning outcomes of students when taught algebra using a social constructivist instructional strategy that are reported elsewhere (e.g., [27]).

Moreover, we utilize an independent sample $t$-test in an attempt to test Hypothesis two and confirm whether or not a significant mean difference exists between the performance scores of male and female senior secondary school students taught algebra using a social constructivist instructional
TABLE 2: Independent sample $t$-test statistics for testing the mean difference in the performance scores of experimental and control group students.

\begin{tabular}{|c|c|c|c|c|c|c|c|c|}
\hline Group & $N$ & Mean & SD & $t$ & $\mathrm{~d} f$ & $p$ & $\begin{array}{c}95 \% \\
\text { CI }\end{array}$ & $d^{2}$ \\
\hline Experimental & 82 & 16.05 & 2.74 & \multirow{2}{*}{10.83} & \multirow{2}{*}{152} & \multirow{2}{*}{$<0.001$} & 3.75 to & \multirow[t]{2}{*}{0.44} \\
\hline Control & 72 & 11.46 & 2.49 & & & & 5.43 & \\
\hline
\end{tabular}

TABLE 3: Independent sample $t$-test statistics for testing the mean difference in the performance scores of male and female students in the experimental group.

\begin{tabular}{lcccccccc}
\hline Experimental & $N$ & Mean & SD & $\begin{array}{c}t \\
\text { value }\end{array}$ & $\mathrm{d} f$ & $p$ & $\begin{array}{c}95 \% \\
\mathrm{CI}\end{array}$ & $d^{2}$ \\
\hline Male & 35 & 17.83 & 2.82 & 6.11 & 80 & $<0.001$ & $\begin{array}{c}2.09 \\
\text { to } 4.12\end{array}$ & 0.318 \\
Female & 47 & 14.72 & 1.77 & & & & to \\
\hline
\end{tabular}

strategy. The ensuing results from this analysis are presented in Table 3.

The results in Table 3 indicate that there is a significant mean difference between the performance scores of male $(M=17.83, \mathrm{SD}=2.82)$ and female students taught algebra using the social constructivist instructional strategy $(M=14.72, \mathrm{SD}=1.77), t(80)=6.11, p<0.001$ (two-tailed), Cohen's $d$ squared of 0.318 . The magnitude of the difference in the means (3.12) is within the $95 \%$ confidence interval (CI: 2.09 to 4.12 ), which can be interpreted to be statistically large. The finding shows that male students outperformed female students when exposed to the same instructional strategy. This could be supportive evidence for a gender discrepancy generally reported on the performance of students in mathematics (e.g., [31]). The finding confirms Hypothesis two with a medium Cohen's effect size of 0.318 . This effect size could be interpreted to mean that $31.8 \%$ of the variance in the performance of students within the experimental group is explained by gender.

\section{Discussion and Conclusion}

The poor academic achievement, especially in secondary school mathematics, has been a great thing of worry to individuals and organizations such as mathematics educators, parents, teachers, educational psychologists, counsellors, government, and the society at large. This is because mathematics is a bedrock of all science and technologicalbased subjects and part of the basic mandatory requirements for entrance into the different institutions of higher learning. The continuous poor performance of students in mathematics at national examinations calls for a serious concerted effort in order to find ways to remedy the situation. To correct this anomaly, a number of programmes and activities, in terms of provision of new mathematics textbooks, different mathematics competitions, workshops, seminars, and conferences, among others, have been embarked upon by different stakeholders. The problem of poor performance in mathematics at the national examinations seems to continue because these interventions are, to some extent, not having a direct bearing on the teaching styles and learners' 
attitude towards the subject. Given that the conventional teaching method is commonly practised in most schools, we argued from an empirical point of view that there is a need to search for more effective instructional strategies which will likely improve students' achievement in mathematics. Thus, this study attempts to provide evidence for the impact of a social constructivist instructional strategy on performance in algebra among secondary school students.

The findings of the current study show that the use of a social constructivist instructional strategy is effective and leads to improved performance of students learning algebra better than the use of conventional method of teaching. This finding is in line with other studies where the efficacy of social constructivist strategies on improved performance has been reported (e.g., [32, 33]). Social constructivist instructional strategies are best known for encouraging critical thinking, innovation, knowledge construction and retention, and greater performance. On the other hand, the conventional method of teaching is associated with limited stimulation of innovative and scientific thinking by encouraging students to cram and reproduce facts which basically inhibit their ability to apply their knowledge and skills to different situations in learning mathematics [1]. Our finding is partly in disagreement with a finding of Samuelsson [34] who reported no significant differences in performance of Swedish children on procedural fluency in mathematics between those taught algebra using the problem-based approach and those taught algebra using the conventional method. However, similar to our finding, he also found improved performance when students' scores of those taught algebra using problem-based and conventional methods are compared on conceptual knowledge, reasoning, and competence in mathematics [34].

Another important finding of the current study shows that there is a difference between the performance scores of male and female secondary school students taught algebra using a social constructivist instructional strategy. From the results obtained, male students performed better than female students when exposed to a social constructivist instructional strategy. This finding conforms to a large body of literature on the gender gap between male and female performance in mathematics (e.g., $[31,35])$. Despite the recent evidence of no substantial gender gap in students' mathematics performance (e.g., [36]), the observed gender gap in the present study may be ascribed to some reasons that are indigenous to our students. First, there is a widespread notion in the country that mathematics is complicated, and this leads to declined interest in the subject among secondary school students. As such, most female students sign up for the subject only because it is compulsory. Perhaps, the lack of interest could pose a challenge for doing well in the subject. Second, mathematics intensive courses such as engineering and physical sciences are usually portrayed as maledominated in higher education. This representation of the STEM courses may lower students' motivation for mathematics at secondary school levels. Moreover, female students have been empirically shown to develop high mathematics anxiety, negative attitudes towards mathematics, and lack of self-efficacy as compared to male students [36-38]. These negative dispositions towards the subject may constitute a reason for the reported gender gap in the present study.
Based on the findings of the current study, it is recommended that teachers should engage students in an active process of learning such as imitative learning or modeling that enhance the ability of the students regardless of gender to construct meanings. This is expected to build solid foundations in basic algebraic manipulations before being exposed to abstract algebraic thinking. They should engage in scaffolding or instructed learning by focusing on students listening and engagement in critical thinking processes that are needed in working with algebraic process tasks. It is further recommended that teachers should encourage collaborative learning or knowledge construction among groups. This will allow students to interact socially, engage in dialogue, construct, and apply algebraic knowledge in a context that involves realworld problems, relevant and interesting to the learners. We conclude this section by acknowledging some potential limitations of the current study.

Despite the strengths of the current study in terms of the relatively large sample size involved and the level of validity checks on the instrument used, some limitations of the study are plausible. For instance, our assumption of relative academic equivalence of both the experimental and the control group students is not tested. The administration of a pretest of mathematics performance to both groups would have been helpful to validate this assumption. However, this was not done and could possibly affect the observed results in the posttest. Moreover, we did not check the unidimensionality assumption of the APT using confirmatory factor analysis or item response theory [39]. This might pose a threat to the construct validity of the instrument. Also, we did not include measurement errors in the analysis as per the $t$-test statistics used for the mean difference. An alternate analysis would have been a latent variable approach in the form of a structural equation modeling that is capable of including measurement errors in the modeling process [40]. Even though the teachers who taught both experimental and control groups are of relatively equal work experience and qualifications, we measured neither their mathematics content knowledge nor pedagogical knowledge which could pose some biases to the findings of our study. We would have swapped the teachers during the treatment period, which is not feasible because only the experimental group teachers were trained to use the social constructivist instructional strategy. Furthermore, it may be difficult to claim 100 percent assurance that the better results for the experiment group are due to the applied instructional approach. There may also be other reasons; for example, the variation in teachers' pedagogical content knowledge, students' motivation, and mental ability. Inasmuch as some of these limitations are plausible, the current study offers potential opportunities for teachers, researchers, and other education stakeholders on the promising efficacy of the social constructivist instructional strategy in improving students' learning outcomes.

\section{Data Availability}

The data used for the present study will be available upon request from the corresponding author. 


\section{Conflicts of Interest}

The authors declare that they have no conflicts of interest.

\section{References}

[1] Y. F. Zakariya, M. O. Ibrahim, and L. O. Adisa, "Impacts of problem-based learning on performance and retention in mathematics among junior secondary school students in Sabon-Gari area of Kaduna state," International Journal for Innovative Research in Multidisciplinary Field, vol. 2, no. 9, pp. 42-47, 2016.

[2] M. S. Kurumeh, "Effects of ethnomathematics approach on students' interest in geometry and mensuration," Abacus: The Journal of the Mathematical Association of Nigeria, vol. 32, no. 1, pp. 103-112, 2007.

[3] U. A. Obioma, "Re-branding the strategies for teaching mathematics: the case of scaffolding," in Proceedings of the 2011 Annual National Conference of Mathematical Association of Nigeria (MAN), Abuja, Nigeria, September 2011.

[4] F. M. Newmann, H. M. Marks, and A. Gamoran, "Authentic pedagogy and student performance," American Journal of Education, vol. 104, 1996.

[5] Y. Nie, G. H. Tan, A. K. Liau, S. Lau, and B. L. Chua, "The roles of teacher efficacy in instructional innovation: its predictive relations to constructivist and didactic instruction," Educational Research for Policy and Practice, vol. 12, no. 1, pp. 67-77, 2013.

[6] E. M. Furtak, T. Seidel, H. Iverson, and D. C. Briggs, "Experimental and quasi-experimental studies of inquiry-based science teaching," Review of Educational Research, vol. 82, no. 3, pp. 300-329, 2012.

[7] S. L. Laursen, M.-L. Hassi, and S. Hough, "Implementation and outcomes of inquiry-based learning in mathematics content courses for pre-service teachers," International Journal of Mathematical Education in Science and Technology, vol. 47, no. 2, pp. 256-275, 2015.

[8] J. H. Nunaki, I. Damopolii, I. Damopolii, N. Y. Kandowangko, and E. Nusantari, "The effectiveness of inquiry-based learning to train the students' metacognitive skills based on gender differences," International Journal of Instruction, vol. 12, no. 2, pp. 505-516, 2019.

[9] M. Cotič and M. V. Zuljan, "Problem-based instruction in mathematics and its impact on the cognitive results of the students and on affective-motivational aspects," Educational Studies, vol. 35, no. 3, pp. 297-310, 2009.

[10] O. Olaoye and E. O. Adu, "Problem-based learning strategies and gender as determinant of grade 9 students' academic achievement in algebra," International Journal of Educational Sciences, vol. 8, no. 3, pp. 485-492, 2015.

[11] C. Wirkala and D. Kuhn, "Problem-based learning in K-12 education," American Educational Research Journal, vol. 48, no. 5, pp. 1157-1186, 2011.

[12] M. M. Marshall, A. L. Carrano, and W. A. Dannels, “Adapting experiential learning to develop problem-solving skills in deaf and hard-of-hearing engineering students," Journal of Deaf Studies and Deaf Education, vol. 21, no. 4, pp. 403-415, 2016.

[13] D. Hammer, "Discovery learning and discovery teaching," Cognition and Instruction, vol. 15, no. 4, pp. 485-529, 1997.

[14] A. d. S. Figueira-Sampaio, E. E. F. dos Santos, and G. A. Carrijo, "A constructivist computational tool to assist in learning primary school mathematical equations," Computers \& Education, vol. 53, no. 2, pp. 484-492, 2009.
[15] J. J. Pear and D. E. Crone-Todd, "A social constructivist approach to computer-mediated instruction," Computers \& Education, vol. 38, no. 1-3, pp. 221-231, 2002.

[16] S. Bell, "Project-based learning for the 21st century: skills for the future," The Clearing House: A Journal of Educational Strategies, Issues and Ideas, vol. 83, no. 2, pp. 39-43, 2010.

[17] P. A. Kirschner, J. Sweller, and R. E. Clark, "Why minimal guidance during instruction does not work: an analysis of the failure of constructivist, discovery, problem-based, experiential, and inquiry-based teaching," Educational Psychologist, vol. 41, no. 2, pp. 75-86, 2006.

[18] O. A. Ladele, "Word problems in algebra: Nigerian junior secondary one students' experience," in Proceedings of the 8th International Conference of Education, Research and Innovation, Seville, Spain, November 2015.

[19] T. Tossavainen, P. Väisänen, J. K. Merikoski, T. Lukin, and H. Suomalainen, "A survey on the permanence of Finnish students' arithmetical skills and the role of motivation," Education Research International, vol. 2015, Article ID 213429, 8 pages, 2015.

[20] B. Hand, D. F. Treagust, and K. Vance, "Student perceptions of the social constructivist classroom," Science Education, vol. 81 , no. 5, pp. 561-575, 1997.

[21] J. S. Kim, "The effects of a constructivist teaching approach on student academic achievement, self-concept, and learning strategies," Asia Pacific Education Review, vol. 6, no. 1, pp. 7-19, 2005.

[22] J. F. Voss, J. Wiley, and M. Carretero, "Acquiring intellectual skills,” Annual Review of Psychology, vol. 46, no. 1, pp. 155-181, 1995.

[23] A. S. Palincsar, "Social constructivist perspectives on teaching and learning," Annual Review of Psychology, vol. 49, no. 1, pp. 345-375, 1998.

[24] L. Vygotsky, Mind in Society: The Development of Higher Psychological Processes, Harvard University Press, Cambridge, MA, USA, 1978.

[25] P. K. Johri, Educational Thought, Anmol Publications, New Delhi, India, 2005.

[26] E. A. Davis and N. Miyake, "Explorations of scaffolding in complex classroom systems," Journal of the Learning Sciences, vol. 13, no. 3, pp. 265-272, 2004.

[27] B. M. Ilyas, K. J. Rawat, M. T. Bhatti, and N. Malik, "Effect of teaching of algebra through social constructivist approach on 7th graders' learning outcomes in Sindh (Pakistan)," International Journal of Instruction, vol. 6, no. 1, pp. 151-164, 2013.

[28] L. Trif, "Training models of social constructivism. Teaching based on developing a scaffold," Procedia-Social and Behavioral Sciences, vol. 180, pp. 978-983, 2015.

[29] C. DeMars, Item Response Theory: Understanding Statistics Measurement, Oxford University Press, New York, NY, USA, 2010.

[30] A. Field, Discovering Statistics Using IBM SPSS Statistics, SAGE Publication, London, UK, 5th edition, 2018.

[31] Y. S. Yoo, "Modelling of factors influencing gender difference in mathematics achievement using TIMSS 2011 data for Singaporean eighth grade students," Asia Pacific Journal of Education, vol. 38, no. 1, pp. 1-14, 2018.

[32] K. J. Bii, M. W. Chris, and T. Jackson, "Effect of collaborative concept mapping teaching strategy on students' achievement and attitudes towards mathematics in selected secondary schools in Kenya," European Journal of Education Studies, vol. 6, no. 5, pp. 135-162, 2019.

[33] E. Molla and M. Muche, "Impact of cooperative learning approaches on students' academic achievement and 
laboratory proficiency in biology subject in selected rural schools, Ethiopia," Education Research International, vol. 2018, Article ID 6202484, 9 pages, 2018.

[34] J. Samuelsson, "The impact of teaching approaches on students' mathematical proficiency in Sweden," International Electronic Journal of Mathematics Education, vol. 5, no. 2, pp. 61-78, 2010.

[35] A. N. Duyilemi and A. O. Bolajoko, "Effects of constructivists' learning strategies on senior secondary school students achievement and retention in biology," Mediterranean Journal of Social Sciences, vol. 5, no. 27, 2014.

[36] S. Rodríguez, B. Regueiro, I. Piñeiro, I. Estévez, and A. Valle, "Gender differences in mathematics motivation: differential effects on performance in primary education," Frontiers in Psychology, vol. 10, p. 3050, 2020.

[37] Y. F. Zakariya, "Development of attitudes towards mathematics scale (ATMS) using Nigerian data-factor analysis as a determinant of attitude subcategories," International Journal of Progressive Education, vol. 13, no. 2, pp. 74-84, 2017.

[38] Y. F. Zakariya, "Development of mathematics anxiety scale: factor analysis as a determinant of subcategories," Journal of Pedagogical Research, vol. 2, no. 2, pp. 135-144, 2018.

[39] Y. F. Zakariya, "Study approaches in higher education mathematics: investigating the statistical behaviour of an instrument translated into Norwegian," Education Sciences, vol. 9, no. 3, p. 191, 2019.

[40] Y. F. Zakariya, "Effects of school climate and teacher selfefficacy on job satisfaction of mostly STEM teachers: a structural multigroup invariance approach," International Journal of STEM Education, vol. 7, no. 1, 2020. 